\title{
A New Path toward a Hybrid Model
}

\author{
Insights from PwC's Italian Experience Centre
}

\author{
Stefano MAGISTRETTI (corresponding author) \\ School of Management - Politecnico di Milano \\ stefano.magistretti@polimi.it \\ Daniel TRABUCCHI \\ School of Management - Politecnico di Milano \\ daniel.trabucchi@polimi.it \\ Claudio DELL'ERA \\ School of Management - Politecnico di Milano \\ claudio.dellera@polimi.it \\ Tommaso BUGANZA \\ School of Management - Politecnico di Milano \\ tommaso.buganza@polimi.it
}

\begin{abstract}
Overview: Implementing Agile principles in large organizations is complex. Indeed, such organizations may struggle to prioritize people over processes, work over documentation, and flexibility over planning. Despite these difficulties, the constantly evolving market pushes established firms toward the adoption of more flexible solutions. The case of PricewaterhouseCoopers $(\mathrm{PwC})$, a large organization in the consultancy industry, shows that firms can implement hybrid methods without the need to restructure the overall organization. The evidence from PwC's experience shows that a number of tactics, such as the creation of a unit specifically dedicated to supporting Agile implementation for the entire firm, can simplify the adoption of Agile principles. The key contribution of this study is in identifying five levers that can help large organizations implement the Agile principles.
\end{abstract}

Keywords: Agile; Agile organizations; Organizational structure; Design thinking; Lean Startup

This is a post-print version of the paper Magistretti, S., Trabucchi, D., Dell'Era, C. and Buganza, T., (2019). A New Path Toward a Hybrid Model: Insights from PwC's Italian Experience Centre. Research-Technology Management, 62(5). doi:10.1080/08956308.2019.1638223 
Innovation is becoming increasingly important in executives' agendas for the organizations they lead (Kahn et al. 2012). However, innovation is a complex undertaking; success requires understanding customer needs while also considering time and cost constraints (Knapp, Zeratsky, and Kowitz 2016; Castellion and Markham 2013; Faraj and Sambamurthy 2006). Indeed, to stay innovative, firms need to adapt internally by embracing flexibility and agility to respond to the evolving outside environment (Barczak, Griffin, and Kahn 2009). Hybrid models can provide this needed flexibility and responsiveness, encourage involvement of customers and other stakeholders in the process, and thus support more success in innovation (Cooper 2016). Nevertheless, such approaches often meet resistance within established organizations, since they tend to challenge the status quo and require different competencies and capabilities than traditional approaches (Birkinshaw 2018).

Thus implementing such models can present challenges from both within and outside. Shedding light on how organizations implement hybrid models and address internal challenges in order to meet external challenges is important for both practitioners and academics. Here, we offer insights derived from an illustrative case of the successful implementation of Agile principles within a large, established consultancy firm, PricewaterhouseCoopers ( $\mathrm{PwC})$. The case shows how $\mathrm{PwC}$ leveraged Agile principles and shifted away from a traditional process to become a hybrid organization without disrupting the overall corporate structure and culture. PwC's results suggest one approach other companies considering such a transformation may wish to consider.

\section{Stage-Gate, Agile, and Other Hybrid Models: The Evolution of Innovation Processes}

Stage-Gate, the leading model for product development and project management, was introduced in the 1980s (Cooper 1990). This model, which applied the anticipation principle to avoid reworking or redirecting processes, is now used by most traditional companies (Cooper 2009). But, at the end of the 20th century, some alternatives began to emerge from the first digital revolution. The software industry required different approaches to product development, given the characteristics of their products. One of those options was Agile. The Agile Manifesto (Beck et al. 2001) summarized in 12 principles the ideal software development experience. Those principles emphasized the role of people over processes, work over documentation, collaboration over contracts, and flexibility over planning. This focus was coherent with emerging calls for more flexibility in product development (Buganza and Verganti 2006; Verganti and Buganza 2005).

Evidence suggests that Agile has improved the typically low success rate of software innovation projects (Misra, Kumar, and Kumar 2009). In fact, its success has attracted the attention of traditional industries, where most innovation initiatives fail to meet time, cost, and quality objectives (Castellion and Markham 2013). As more physical product companies have experimented with Agile, it has been increasingly considered a promising management approach. Further, Agile methods have been quantitatively proven to be positively related to new product quality and on-time and on-budget completion (Bianchi, Marzi, and Guerinim 2018). 
More recently, a new approach has emerged, one that combines Stage-Gate and Agile. In 2014, Cooper - the father of the Stage-Gate model-proposed a revision of the model that emphasizes the "Triple A" of attributes: Adaptive, Agile, and Accelerated (Cooper 2014). This adaptation, Cooper suggested, was better able to address new competitive scenarios and the new product development challenges they present. That initial proposal has evolved into a full hybrid model that implements Agile Scrum cycles at the execution level, within a strategic Stage-Gate process (Sommer et al. 2015). This hybrid is characterized by nine main elements: three key practices (sprint, daily scrum, and retrospective meeting), three tools (product backlog, sprint board, and burn-down chart), and three vital roles (individual members, Scrum master, and product owner) (Cooper and Sommer 2016a). The effectiveness of the Agile-Stage-Gate hybrid process has been empirically investigated in different settings, including for the development of physical B2B products (Cooper and Sommer 2016a) and in B2C companies (Cooper and Sommer 2016b).

Another set of emerging hybrids, these often inspired by the Lean Startup methodology (Ries 2011; Ghezzi 2018), is evident in proprietary processes such as General Electric's Fastworks process (Power 2014). Fastworks applies Agile principles to accelerate the development process, based on "quick" deliverables and continuous learning. The process has had an impact on the entire organization, changing the way in which GE manages its relationships with suppliers and approaches the financial aspects of development projects (Power 2014). Similarly, J\&J's Pilot, Pivot and Pitch process draws on Lean Startup and Agile principles to encourage the company to think like a startup and use experimentation and customer centricity to power innovation (Guinan and Parise 2017). Amazon's principle of "working backwards" from customer needs is similarly motivated; in that process, ideas are forced into visualization in the first stage, go through presentations in the second, and enter a traditional development process only at the end of this early experimental work. (Dyer and Gregersen 2017).

Google's Design Sprint is another such system. Design Sprint encompasses elements of Agile, design thinking, and Lean Startup (Knapp, Zeratsky, and Kowitz 2016). It builds on design thinking principles regarding creativity and exploration of possibilities and embraces the continuous experimentation approach of Lean Startup. These elements are combined with Agile's discrete time horizons to ensure rapid progress. Combining these elements with a rigid, facilitated process allows practitioners to produce a minimum viable product (MVP) in just five days.

These examples show how many companies start working on the integration between traditional and alternative processes, by combining elements of different approaches to meet their particular needs or cultural constraints. Despite these successes, companies embarking on such a journey still often meet substantial resistance to the diffusion of the hybrid model. As Cooper and Sommer (2018) point out, with regard to the Agile-StageGate hybrid, "The greatest challenges are management skepticism and finding the dedicated resources to make this new model work" (p. 25).

Given this skepticism, even demonstrated performance improvements may not be enough to drive adoption of hybrid models. One of the few studies in the service field shows that 
five conditions are necessary to support successful implementation of a hybrid model (Birkinshaw 2018):

1. The willingness to change the corporate culture,

2. The ability to manage stakeholders,

3. The ability to build a proper structure to involve and manage customers,

4. The ability to properly manage the supervision and autonomy of employees, and

5. The ability to provide sufficient development and growth opportunities for employees.

The broad and encompassing nature of these conditions highlights the difficulties of implementing these models in established companies. However, PwC's experience suggests that there may be another way, an avenue to the dissemination of a hybrid approach that does not require upending the company's entire culture and structure in one effort.

\section{The Study}

We focus on a single in-depth case study (Yin 2013) of a service-industry company's adoption of a new approach to product development. Following Siggelkow (2007), we selected this company as a subject of our study for two main reasons: 1) the company has successfully adopted a new, hybrid approach in-house, and 2) it is service oriented, offering a contrast to the majority of studies, which focus on product-oriented firms.

$\mathrm{PwC}$ is an international consulting firm, one of the Big Four in its sector. Its international network delivers assurance, tax, and advisory services to other large organizations. Founded in 1998, it operates in more than 158 countries with more than 250,000 employees. The case study focused on the creation and role of a specific business unit: PwC's Experience Centres.

Data were collected at PwC's Italian Experience Centre, the largest in Europe, which was established in Rome in 2016 under the control of PwC Italy. This center was the first and the largest in Europe, following the first opened in Miami, in late 2015, and now it is part of a network of more than 35 Experience Centres all over the world. The data collection process, which lasted one year, encompassed both primary and secondary sources to allow triangulation of the data (Jick 1979). We conducted semistructured interviews with two partners, the director of the Italian Experience Centre, and three senior and two junior managers. We also undertook two direct observations to understand how Experience Centre managers facilitate the adoption of Agile principles in their projects and conducted three company visits, two to the Italian headquarters and one to the Experience Centre, to directly observe how services are delivered. Finally, we analyzed secondary sources, including documents and press releases, to obtain further evidence regarding the creation and performance of the Experience Centre.

The authors recorded, transcribed, and analyzed data from the interviews and observations (Miles and Hubermann 1994; Saldaña 2015). In particular, all the information gathered was grouped in a single repository and organized into clusters. The main sections reported here include historical data about the organization and culture of the company, the structure of the Experience Centre, people employed at the center, the 
structure of the process, and examples of its application. These data were analyzed individually by each researcher, and then authors gathered to discuss main insights. The findings were then shared with PwC's managers to validate the information before moving to theorization.

This in-depth investigation allowed us to gather information on the way projects are managed from both organization and process perspectives and to perform a rigorous within-case analysis (Eisenhardt 1989) with the aim of contributing to both theory and practice.

\section{PwC and the Creation of the Experience Centre}

PwC's Experience Centre was created in response to a growing belief in the field that new approaches were needed to allow the company and its consultants to react more quickly to evolving customer needs. As a partner told us, the company's existing approach was highly structured and inflexible: "Traditionally in $\mathrm{PwC}$, we tend to follow a structured flow of activity to consult our clients. This process goes through scheduled reviews with the clients to share and validate the work performed and so advance in the project." This alternation of working phases and project reviews has some limitations. Interviews showed that the main issue $\mathrm{PwC}$ consultants faced with this approach was identifying and addressing clients' incorrect initial assumptions, which often started projects off in the wrong direction. These false starts mainly occurred because consultants relied on clients' identification of problems in designing the project. As the director of the Italian Experience Centre told us, "We started too many projects with clients that were convinced about the fact that they had a problem but then after a few review meetings we realized that the real challenge they faced was completely different." In other words, PwC had no problem-framing process to make sure it was solving the right problems for its clients. Moreover, the misalignment between clients' requests and the firm's solutions sometimes became evident only in the later stages of the project, causing rework and delays. At today's market pace, where timing and effectiveness are essential, this kind of misfire can be perilous for large consultancies.

The center's primary focus is on designing customer experiences. As the director of the center told us, "In this lab, we do several things from co-creation workshops to interviews with real users, from the crafting of artisanal prototypes to testing them." The establishment of the Rome PwC's Experience Centre in 2016 was motivated by the growing demand from consultants for tools to enable more rapid responses to client requests and more flexibility in the ideation and testing of customer experiences. Envisioned as a separate unit that autonomously manages both financial and nonfinancial resources, the Centre offers services to both external and internal clients (such as other PwC consultants). The Director of the Centre defined this second perspective-a consultancy service targeting consultants - as "meta-consultancy": "We support both our Italian consultants in their projects and we also perform our own projects. So, we have this double aim as consultants and meta-consultants." The meta-consulting perspective is crucial for the success of the PwC's Experience Centre because it allows employees to stay updated and aligned with the knowledge and projects other PwC consultants manage. Nevertheless, the need for an independent revenue stream forces the Experience 
Centre to take on traditional consultancy projects as well. These independent projects also allow center employees to experiment with new approaches and methodologies that can then be then transferred to the meta-consulting projects.

The center supports its offerings with a unique configuration of assets, in terms of both physical and human resources, to enable it to support a variety initiatives and interactions with diverse clients and even end customers. The center's space includes four main facilities: the workshop room, the Fab-Lab, the testing room, and the auditorium. This array of facilities allows the center to support all phases of customer experience development, from invention to market launch.

A heterogeneous and diverse group of employees works in those spaces, from psychologists to UX/UI designers, software developers, and mathematicians. The director of the center believes that this diversity of experience is one of the most important elements of the Centre's success. As he told us, "Without a plurality of job profiles, a place like this cannot survive one day. We need to guarantee the availability of a good set of skills at any time for each project. This is because the team must be ready to support the different projects in every moment. Moreover, by taking part every week to different projects they learn different industries and different things that empower them and let them growth." These employees tend to jump in and out of projects as their particular skills and experience are needed.

Furthermore, the center acts differently from the rest of the company in terms of team configuration; rather than $\mathrm{PwC}$ 's traditional advisory team composed of partner, senior consultant, and junior analyst, team composition is continuously defined and redefined to meet specific project needs. This reshuffling offers employees enormous opportunities for growth to the employees, because they engage in many different challenges and learn the peculiarities of different industries and clients, as well as exploring different roles. The culture of the center is also much more flexible and less hierarchical than the rest of the company. The center has no private offices and new project teams are created without hierarchy. Rather, the team roster focuses on the experience of the employees in the specific area of the project.

PwC conceived the Experience Centre to manage two different types of initiatives. To support advisory projects, Experience Centre managers facilitate pre-project workshops that use design thinking as a problem-framing mechanism, allowing both the client and the $\mathrm{PwC}$ team to identify and understand the real challenge at the heart of the project and thus reducing the misalignment between perceived and actual problems. The approach to these kinds of projects is a hybrid of PwC's traditional way of doing consultancy with the Experience Centre's more flexible process; the customer is directly involved in the cocreation activity together with consultants. The center's facilities are also available to support projects in the later stages. For example, as the Director of the Centre highlighted, during the first year of activity, numerous testing sessions were performed to support either particular stages of the consulting process (front end or testing, for example) or end-to-end projects. 
These services are offered in packages that range from one-day to five-day workshops and monthly projects. The duration of a project depends on its scope and the clients' needs. This array of services allows the center to manage different stakeholders according to each stakeholder's needs. For instance, if the client needs to test a solution that has already been developed, the testing workshop can be used to perform usability tests during the deployment phase. For more complex or ill-defined challenges, the five-day workshop supports clients and consultants ideating, prototyping, and implementing a solution.

The center also offers both consultants and clients the opportunity to visit the Experience Centre to familiarize themselves with its services and increase awareness of its capabilities. According to one Customer Experience Partner, "What we discovered as soon as we opened the PwC's Experience Centre is that it's hard to sell customer experience consultancy services both internally (to other consultants) and externally (to clients). So, we decided to include among all the different services and workshops the package named 'Experience Centre Introduction,' a package that covers between two and four hours in which the consultants or the client can come and meet the team and explore the services. This is important because we need to let the others know what we do here, including other PwC consultants."

In its four years of activity, the center has grown steadily. The number of projects completed has increased each year $(+230$ percent in $2017,+30$ percent in 2018 , and +90 percent in the first part of 2019), and that growth has powered a growth in revenues $(+50$ percent in $2017,+25$ percent in $2018,+35$ percent in 2019). The Centre's employee base has more than doubled, as well, from 16 in 2016 to 35 in 2019.

Two projects in the center's first year illustrate the value it adds for PwC: the redesign of the in-store experience for a supermarket chain and the definition of new processes and procedures for an energy company. The support of the Experience Centre allowed consultants and the client in the first case to better understand customers' real needs and propose and prototype tangible solutions in just five days. The co-existence of the FabLab and the test room allowed the team to envision, embody, and test the solution faster, radically reducing the project's start time. In the energy company project, the colocation of managers and onsite engineers allowed the team to map eight core processes for maintenance in detail in just two days. Leveraging templates and LEGO construction blocks, energy company employees were able to detail the situation in two days, compared to the weeks or months usually needed in the traditional business process reengineering approach, according to the Experience Centre manager.

\section{The Experience Centre as On-Demand Hybrid Service}

PwC's Experience Centre demonstrates how a large service-oriented firm implemented a hybrid approach to allow for more responsiveness and flexibility in its development process. This new approach to the company's existing organizational structure, intended to make it more agile, can be of value to both practitioners and academics. The case also offers broader insights related to the integration of new organizational dynamics into existing processes. The Experience Centre operates like an on-demand service that supports the overall organization by providing a framework and venue for implementing 
a different, more agile approach when it is needed. It functions as a component of the larger business whose role it is to embrace and disseminate alternate principles from those of the main business.

Flexible and Lean development methodologies have been found to be particularly successful (Bianchi, Marzi, and Guerinim 2018). However, they are difficult to implement in large companies, mainly due to cultural resistance and the momentum that coheres around established processes (Birkinshaw 2018). PwC and the Experience Centre suggest one possible solution to these challenges - a new function inserted into the organizational structure to provide access to hybrid or alternative development principles when and where they are needed or helpful.

\section{An Organizational Servant Leader}

Previous studies on Agile approaches and hybrid methods often point out the role of the Scrum master-the facilitator of the methodology-as a servant leader for the development project (Cooper 2016). Unlike a project manager, the scrum master's job is not to manage the team, but to ensure the Agile methodology is fully adopted and to ease the team's work flow. Similarly, the facilitator's role in Design Sprint is to control and manage the sprints from a methodological perspective, without influencing the decisionmaking process (Knapp, Zeratsky, and Kowitz 2016). PwC's Experience Centres play a similar role on a macro level; they serve the other units in the business, allowing them to access an alternate development philosophy without having to challenge the overall organization chart or organizational culture.

This operational choice is particularly in line with the literature on ambidexterity literature (for instance, Tushman, and O'Reilly 1996). Specifically, the on-demand approach is akin to structural ambidexterity (Turner, Swart, and Maylor 2013), which allows an organization to pursue two apparently contradictory agendas; here, it allows the organization to implement apparently conflicting elements as needed, via a dedicated unit. Such an approach may represent a powerful first step in bringing alternate methods into established organizations, alongside or in combination with traditional development processes.

\section{The Right Business Model to Sustain Change}

The PwC's Experience Centre offers several insights on how to sustain a new function in an existing organization, and empower it to play a relevant role in internal processes. The center's meta-consultancy practice, which provides services to other units and their projects (including the various units that engage in traditional consultancy projects and traditional development processes), helps shape the individual development project, but it also has a wider impact on both organizational performance and organizational culture (Figure 1). 

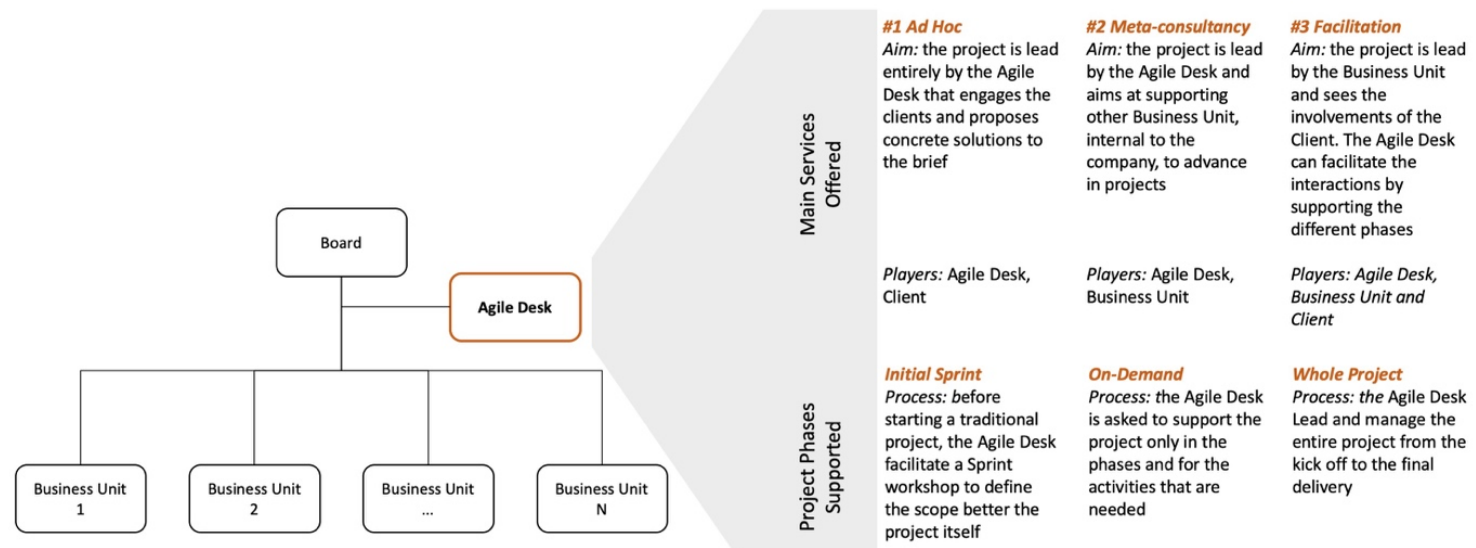

Figure 1.-The Experience Centre's place in PwC

First, by making itself available for meta-consultancy, the Experience Centre helps projects escape early-stage traps. Involving customers early on in a new way helps consultants better understand their needs and address the right problems from the start. The change may seem minor, but the impact is far from small. Most innovation projects fail because they do not fulfill customers' expectations (Castellion and Markham 2013). Adding a sprint stage at the beginning of the project development process leads to more engaged and aware customers and a better-defined project scope - and ultimately to more successful projects.

Moreover, the on-demand nature of the Experience Centre's services is particularly relevant from a cultural perspective: it makes the alternative system a choice. Each unit can decide when and how to involve the Experience Centre in a project. Over time, the alternative principles are diffused throughout the organization-leading to culture change without disruption. Offering consultants and customers the opportunity to visit the Experience Centre to better understand what they do and how they work further augments this effect. This approach is interesting from the change management perspective, as it suggests a way in which change may be managed top-down and bottomup simultaneously: the new direction is set by the top, but employees can decide when and if to embrace it (Beer and Nohria 2000).

In other words, this case offers an interesting paradigm shift in the implementation of radical change management projects. Traditionally, to implement radical changes in the organization, companies have tended to work on big culture change initiatives, with the goal of enabling organizational change by catalyzing culture change (Canterino et al. 2016; Quinn and Cameron 1983). In other words, it is a stepwise approach to change: first the culture, then the organization. Nevertheless, our case suggests something truly different: modifying the organization by adding a new function to gradually foster a cultural change. 


\section{Takeaways: Five Levers to Enhance the Dissemination of Hybrid Systems}

The case of the PwC's Experience Centre may offer a way to overcome some of the cultural barriers that may hinder the adoption of hybrid processes. A generalization of the key characteristics of the Experience Centre suggest five main levers of change with regard to organizational structure and mechanisms (Figure 2):

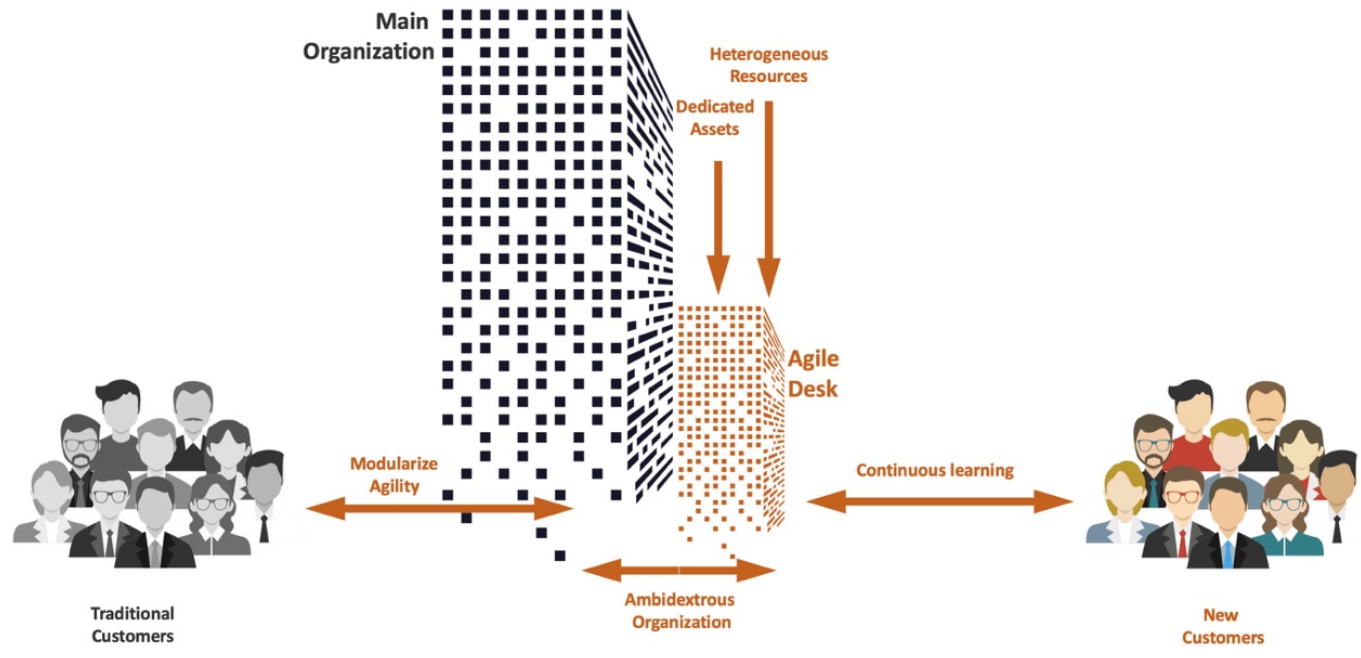

Figure 2.-Five levers to enhance the dissemination of alternative development methods

Ambidextrous organization. Established companies tend to have a cultural orientation toward traditional approaches and processes and to resist new methods focused on flexibility and agility. Developing a dedicated unit like the Experience Center is a potential lever to foster cultural ambidexterity and enable gradual change. The case shows how the center provided this flexibility by taking on different types of projects and educating internal clients about its capabilities.

Dedicated assets. New development approaches require specific assets and tools, such as flexible rooms, wide spaces, and office designs that support interaction and collaboration, like the Fab-Lab and testing areas in the Experience Centre. Creating dedicated assets to support these needs enhances ambidexterity, while providing the necessary conditions to allow the new method to succeed.

Heterogeneous staffing. New methods require different backgrounds, disciplines, and perspectives than established approaches. Hiring dedicated people with diverse backgrounds will enhance the adoption of the new method. At the Experience Centre, the variety of expertise in the employees is a differentiating factor for the success of the initiative.

Continuous learning. The on-demand service cannot be merely a methodological tool. The new function must be free to experiment and continually learn how to respond to internal challenges; having its own market, as the Experience Centre does, enhances this outcome. 
Modularization. Engaging with the new or hybrid method should be a choice for each project. Existing units should be encouraged - but not required - to approach the ondemand service when its capabilities could enrich a project. In that way, the methodology can be diffused through the organization without forcing a change in the status quo. This is evident in the Experience Centre as it can support initial design sprint or advanced stages of projects according to the needs of the client whatever it is internal or external to PwC.

\section{Conclusion}

PwC's Experience Centre suggests a powerful mechanism to establish alternative development processes within an established firm. It differs from traditional change management approaches, since the new approach is not forced from the top-indeed, employees have the opportunity to choose whether and when they want to adopt it. Moreover, because the Experience Centre has its own markets and customers, this approach may even generate new customers and new revenue flows.

In order to implement this approach, companies need to be ready to dedicate resources to finding the right people to support the new Experience Centre, creating the right facility, and building the right attitude toward the method's core principles. Ultimately, the message is that established companies can adapt new processes without enduring a structured - and lengthy - change management process. Instead, the right attitude to implementing a new set of development principles may be itself agile (that is, on demand).

\section{Acknowledgment}

The authors would like to acknowledge all the practitioners (especially Andrea Pivetta) who collaborated with us during the infield data gathering.

\section{References}

Barczak, G., Griffin, A., Kahn, K.B., 2009. Perspective: trends and drivers of success in NPD practices: results of the 2003 PDMA best practices study. Journal of Product Innovation Management 26 (1), 3-23.

Beck, K., Beedle, M., Van Bennekum, A., Cockburn, A., Cunningham, W., Fowler, M., Grenning, J., Highsmith, J., Hunt, A., Jeffries, R., and Kern, J. 2001. Manifesto for Agile Software Development. https://moodle201617.ua.es/moodle/pluginfile.php/80324/mod_resource/content/2/agilemanifesto.pdf

Beer, M., and Nohria, N. 2000. Cracking the code of change. Harvard Business Review, 78(3): 133-141.

Bianchi, M., Marzi, G., and Guerini M. 2018. Agile, Stage-Gate and their combination: Exploring how they relate to performance in software development. Journal of Business Research, May 10. https://doi.org/10.1016/j.jbusres.2018.05.003

Birkinshaw, J. 2018. What to expect from Agile. MIT Sloan Management Review 59(2): $39-42$. 
Buganza, T., and Verganti, R. 2006. Life-cycle flexibility: How to measure and improve the innovative capability in turbulent environments. Journal of Product Innovation Management 23(5): 393-407.

Canterino, F., Shani, A. B., Coghlan, D., and Brunelli, M. S. 2016. Collaborative management research as a modality of action research: Learning from a mergerbased study. The Journal of Applied Behavioral Science 52(2): 157-186.

Castellion, G., and Markham, S. K., 2013. Perspective: New product failure rates: Influence of argumentum ad populum and self-interest. Journal of Product Innovation Management 30(5): 976-979.

Cooper, R. G. 1990. New products: What distinguishes the winners? ResearchTechnology Management 33(6): 27-31.

Cooper, R. G. 2009. How companies are reinventing their idea-to-launch methodologies. Research-Technology Management 52(2): 47-57.

Cooper, R. G. 2014. What's next? After Stage-Gate. Research-Technology Management 57(1): 20-31.

Cooper, R. G. 2016. Agile-Stage-Gate hybrids: The next stage for product development. Research-Technology Management 59(1): 21-29.

Cooper, R. G., and Sommer, A. F. 2016a. Agile-Stage-Gate: New idea-to-launch method for manufactured new products is faster, more responsive. Industrial Marketing Management 59:167-180.

Cooper, R. G., and Sommer, A. F. 2016b. The Agile-Stage-Gate hybrid model: A promising new approach and a new research opportunity. Journal of Product Innovation Management 33(5): 513-526.

Cooper, R. G., and Sommer, A. F. 2018. Agile-Stage-Gate for manufacturers: Changing the way new products are developed. Research-Technology Management 61(2): $17-26$.

Dyer, J. and Gregersen, H. 2017. How does Amazon stay at day one? Forbes, August 8. www.forbes.com $\% 2 \mathrm{Fsites} \% 2 \mathrm{Finnovatorsdna} \% 2 \mathrm{~F} 2017 \% 2 \mathrm{~F} 08 \% 2 \mathrm{~F} 08 \% 2 \mathrm{Fhow}-$ does-amazon-stay-at-day-one\%2F\&usg=AOvVaw17RF4H9k9klbz83DxDmaOJ

Eisenhardt, K. M. 1989. Building theories from case study research. Academy of Management Review 14(4): 532-550.

Faraj, S., and Sambamurthy, V. 2006. Leadership of information systems development projects. IEEE Transactions on Engineering Management 53(2): 238-249.

Ghezzi, A. 2018. Digital startups and the adoption and implementation of Lean Startup approaches: Effectuation, bricolage and opportunity creation in practice. Technological Forecasting and Social Change, September 24. https://doi.org/10.1016/j.techfore.2018.09.017

Guinan, P. J., and Parise, S. 2017. Pilot, Pivot, and Pitch: Applying a rapid value realization approach to designing digital solutions at Johnson \& Johnson. Technology, Operations \& Information Management Working Papers 9-2017. https://digitalknowledge.babson.edu/toimwp/11/

Jick, T. D. 1979. Mixing qualitative and quantitative methods: Triangulation in action. Administrative Science Quarterly 24(4): 602-611.

Kahn, K. B., Barczak, G., Nicholas, J., Ledwith, A., and Perks, H. 2012. An examination of new product development best practice. Journal of Product Innovation Management 29(2): 180-192. 
Knapp, J., Zeratsky, J., and Kowitz, B. 2016. Sprint: How to Solve Big Problems and Test New Ideas in Just Five Days. New York: Simon and Schuster.

Miles, M. B., and Huberman, M., 1994. Qualitative Data Analysis: An Expanded Sourcebook. Thousand Oaks, CA: Sage Publications.

Misra, S. C., Kumar, V., and Kumar, U. 2009. Identifying some important success factors in adopting Agile software development practices. Journal of Systems and Software 82(11): 1869-1890.

Power, B., 2014. How GE applies Lean Startup practices. Harvard Business Review, April 23. https://hbr.org/2014/04/how-ge-applies-lean-startup-practices

Quinn, R. E., and Cameron, K., 1983. Organizational life cycles and shifting criteria of effectiveness: Some preliminary evidence. Management Science 29(1): 33-51.

Ries, E. 2011. The Lean Startup: How Today's Entrepreneurs Use Continuous Innovation to Create Radically Successful Businesses. New York: Crown Business.

Saldaña, J. 2015. The Coding Manual for Qualitative Researchers. Thousand Oaks, CA: Sage Publications.

Siggelkow, N. 2007. Persuasion with case studies. Academy of Management Journal 50(1): 20-24.

Sommer, A. F., Hedegaard, C., Dukovska-Popovska, I., and Steger-Jensen, K. 2015. Improved product development performance through Agile/Stage-Gate hybrids: The next-generation Stage-Gate process? Research-Technology Management 58(1): 34-45.

Turner, N., Swart, J., and Maylor, H. 2013. Mechanisms for managing ambidexterity: A review and research agenda. International Journal of Management Reviews 15(3): $317-332$.

Tushman, M. L. and O’Reilly, C. A. (1996) 'Ambidextrous Organizations: Managing Evolutionary and Revo- lutionary Change', California Management Review 38(4): 8-30.

Verganti, R., and Buganza, T. 2005. Design inertia: Designing for life-cycle flexibility in Internet-based services. Journal of Product Innovation Management 22(3): 223237.

Yin, R. K. 2013. Case Study Research: Design and Methods. Thousand Oaks, CA: Sage Publications.

\section{Bios}

Stefano Magistretti is a postdoctoral researcher in design and innovation management at the School of Management, Politecnico di Milano, and a senior researcher in the LEAIN'Lab, the Laboratory of LEAdership, Design, and INnovation. Within the School of Management, he is also a member of the research development platform for the Observatory "Design Thinking for Business." He has published journal papers, conference articles, and a chapter in an edited book on the topic of technology innovation, design management, and design thinking. stefano.magistretti@polimi.it

Daniel Trabucchi is a postdoctoral researcher at the School of Management, Politecnico di Milano, where he also serves as a senior researcher in the LEADIN'Lab, the Laboratory for Leadership, Design and Innovation. His research interests are focused in innovation management, especially digital two-sided platforms and digital services. His research has been published in peer-reviewed journals such as Technological Forecasting 
and Social Change, Internet Research, Research-Technology Management, Creativity and Innovation Management, Technology Analysis and Strategic Management, and European Journal of Innovation Management; he is also a reviewer for many of these journals.daniel.trabucchi@polimi.it

Claudio Dell'Era is an associate professor in design strategy at the School of Management, Politecnico di Milano, and cofounder of LEADIN'Lab, the Laboratory of LEAdership, Design and INnovation. He is also director of the Observatory "Design Thinking for Business" in the School of Management. His is concentrated in the areas of design thinking and design strategy. He has published more than 100 journal papers, conference articles, and book chapters. His work has appeared in journals such as Entrepreneurship Theory and Practice, Journal of Product Innovation Management, Long Range Planning, and Industry \& Innovation, among others. claudio.dellera@polimi.it

Tommaso Buganza is an associate professor of leadership and innovation at the School of Management, Politecnico di Milano, and a cofounder of LEADIN'Lab, the Laboratory for Leadership, Design and Innovation. He is responsible for the Project Management Academy and coordinates the innovation training area at MIP (Politecnico di Milano Graduate School of Business). He is a member of the scientific committee of the International Product Development Management Conference. His research, which explores the intersection between technological innovation and leadership, has been published in peer-reviewed journals such as Journal of Product Innovation Management, International Journal of Project Management, and Technological Forecasting and Social Change. tommaso.buganza@polimi.it 